\title{
On the Microstructural Development in Platinum-Modified Nickel- Aluminide Bond Coats
}

\author{
S. Darzens \\ University of Delaware
}

Anette M. Karlsson

Cleveland State University, a.karlsson@csuohio.edu

Follow this and additional works at: https://engagedscholarship.csuohio.edu/enme_facpub

Part of the Mechanical Engineering Commons

How does access to this work benefit you? Let us know!

\section{Publisher's Statement}

NOTICE: this is the author's version of a work that was accepted for publication in Surface and Coatings Technology. Changes resulting from the publishing process, such as peer review, editing, corrections, structural formatting, and other quality control mechanisms may not be reflected in this document. Changes may have been made to this work since it was submitted for publication. A definitive version was subsequently published in Surface and Coatings Technology, 177, , (01-30-2004); 10.1016/j.surfcoat.2003.09.001

\section{Original Citation}

Darzens, S., and Karlsson, A. M., 2004, "On the Microstructural Development in Platinum-Modified NickelAluminide Bond Coats," Surface and Coatings Technology, 177-178pp. 108-112.

This Article is brought to you for free and open access by the Mechanical Engineering Department at EngagedScholarship@CSU. It has been accepted for inclusion in Mechanical Engineering Faculty Publications by an authorized administrator of EngagedScholarship@CSU. For more information, please contact library.es@csuohio.edu. 


\title{
On the microstructural development in platinum-modified nickel- aluminide bond coats
}

\author{
S. Darzens, A.M. Karlsson* \\ Department of Mechanical Engineering, University of Delaware, Newark, DE 19716, USA
}

\section{Introduction}

Incorporating thermal barrier coatings (TBCs) in gas turbines for propulsion and power generation potentially allows for increase in both gas temperatures and gas turbine life, thus increasing fuel economy and reducing life cycle cost. However, this potential is compromised by premature failures of TBCs that are frequently observed in commercial systems. The premature failures are typically associated with spalling of the coating, but the details of the mechanisms are not completely understood. These failures can only be avoided by developing a fundamental understanding of the failure mechanisms to guide redesign of the coating systems.

The lack of understanding of the failure mechanisms is due to the complex, multilayered structure of TBCs, consisting of a superalloy substrate, a bond coat, a thermally grown oxide (TGO) and a ceramic top coat. The superalloy sustains the mechanical load, while the top coat acts as the thermal insulator. The TGO is a reaction product, formed by oxidation of the bond coat and consists of $\alpha$-alumina. In order to protect the superalloy from oxidation, the bond coat provides the system with aluminum to form the TGO. Consumption of $\mathrm{Al}$ in forming $\mathrm{Al}_{2} \mathrm{O}_{3}$ leads to depletion of $\mathrm{Al}$ in the

\footnotetext{
*Corresponding author. Tel.: +1-302-831-6437; fax: +1-302-8313619.

E-mail address: karlsson@me.udel.edu (A.M. Karlsson).
}

bond coat, resulting in the evolution of the bond-coat microstructure. Thus, the thermo-mechanical properties of the bond coat change during use. As a consequence, the overall properties of the thermal barrier system also evolve during service.

A large class of failures is associated with the growth of the TGO [1-6]. As this layer is formed at high temperature, it is subjected to thickening as well as lengthening growth [7]. The lengthening component may be interpreted as new alumina forming at the grain boundaries of the existing grains (Fig. 1) [4,7-9].

A particularly interesting failure mode occurs when the lengthening component of the TGO growth results in out-of-plane displacements that change on a cycleby-cycle basis. This eventually leads to system failure. This phenomenon has recently received considerable attention [4,8-12], for Pt-modified nickel-aluminide (Pt$\mathrm{NiAl})$, and has also been observed for MCrAlYs $[13,14]$. The current understanding of the failure mode - based on experimental, numerical and analytical studiesshows that there are several essential conditions that together cause the development of the morphological features [12]. These are (i) thermal mismatch between bond coat and TGO; (ii) thermal cycling; (iii) initial imperfections in the bond-coat/TBC interface; (iv) lengthening component of TGO growth; (v) yielding of the bond coat and (vi) high temperature creep of the TGO. In addition to these essential conditions, there are 


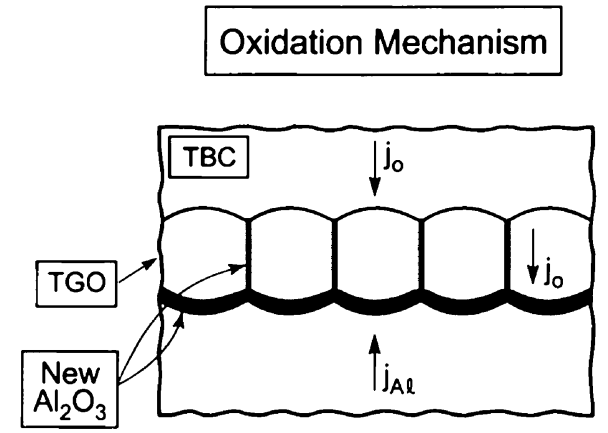

Fig. 1. Formation of new oxide during TGO growth. The lengthening of the oxide scale observed experimentally may be due to new oxide forming at the grains boundaries [4,7-9].

a range of conditions and properties that may accelerate or dampen the change in morphology. Of particular interest for this study will be one type of phase transformation that occurs in the platinum-aluminide bond coat.

Two types of phase transformations are observed in Pt-NiAl: martensitic phase transformation of the $\beta$-phase $[15,16]$, which is reversible during thermal cycling, and transformation from the initial $\beta$-phase to $\gamma^{\prime}$-phase, which is non-reversible.

The response of the systemdue to the martensitic transformation was investigated in Refs. [17,18], and it was seen that it creates a complicated, non-linear system response. For example, the thermal mismatch between the bond coat and the substrate can be enhanced by the phase transformation, resulting in accelerated morphological changes.

The transformation of $\beta$-phase to $\gamma^{\prime}$-phase near the $\mathrm{TGO} /$ bond-coat interface is mainly due to the depletion of aluminum as the $\mathrm{Al}$ diffuses out to form the TGO at the bond-coat surface [20], but also due to diffusion of $\mathrm{Ni}$ to the bond coat fromthe superalloy. The thermomechanical properties - such as thermal expansion and yield strength - are quite different for the two phases. Observations indicate that, when both phases are contiguous with the TGO, instability propagations occur preferentially next to the $\beta$-phase (Fig. 2) $[4,20]$.

In the following, we will present numerical simulations that rationalize the observations relating to the presence of $\beta$-phase and $\gamma^{\prime}$-phase, while simultaneously provide insights about the role of bond-coat microstructure in TBC failure.

The interplay between the TGO instability and crack growth in the TBC defines the scope of the present analysis. Namely, upward displacements of the TGO at the periphery of interface imperfections cause the TGO to 'push-up' the TBC, causing cracks in the TBC to extend and coalesce $[4,5,8,10]$. In this paper, the top coat is ignored in the simulations. The effect of the top coat is investigated in a separate study [21].

\section{Simulation protocol}

The simulation protocol has been described in detail elsewhere [9]. The main features are as follows.

The bond coat has a temperature-dependent yield strength that diminishes rapidly with increase in temperature from ambient to approximately $800{ }^{\circ} \mathrm{C}$ and thereafter remains essentially invariant [19]. In this case,
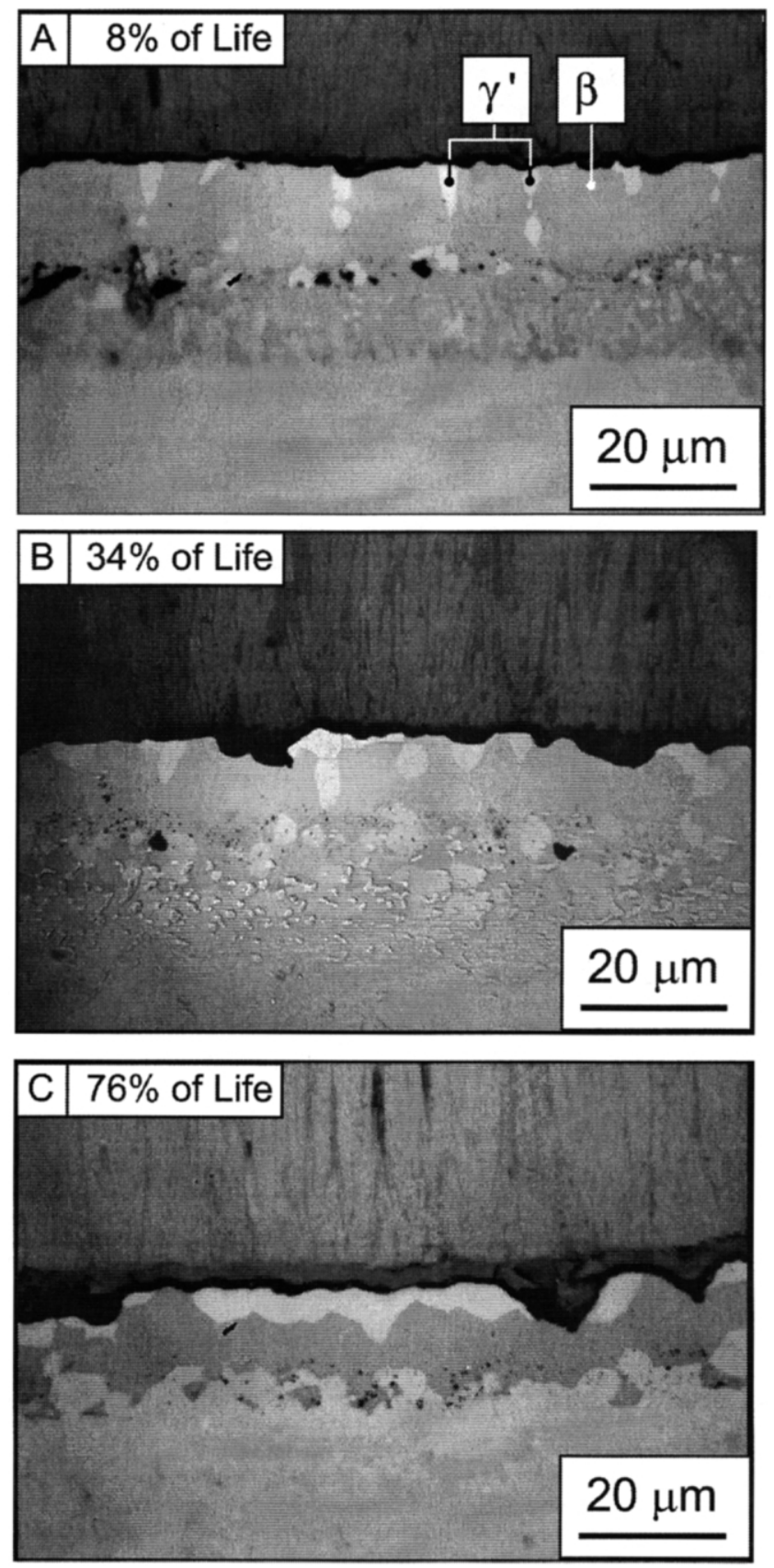

Fig. 2. Optical image of an etched cross-section of a furnace cycle test specimen at different fraction of life, showing the location of the $\beta / \gamma^{\prime}$-phases relative to the TGO instability. (a) $8 \%$ of life; (b) $34 \%$ of life and (c) $76 \%$ of life [20]. 


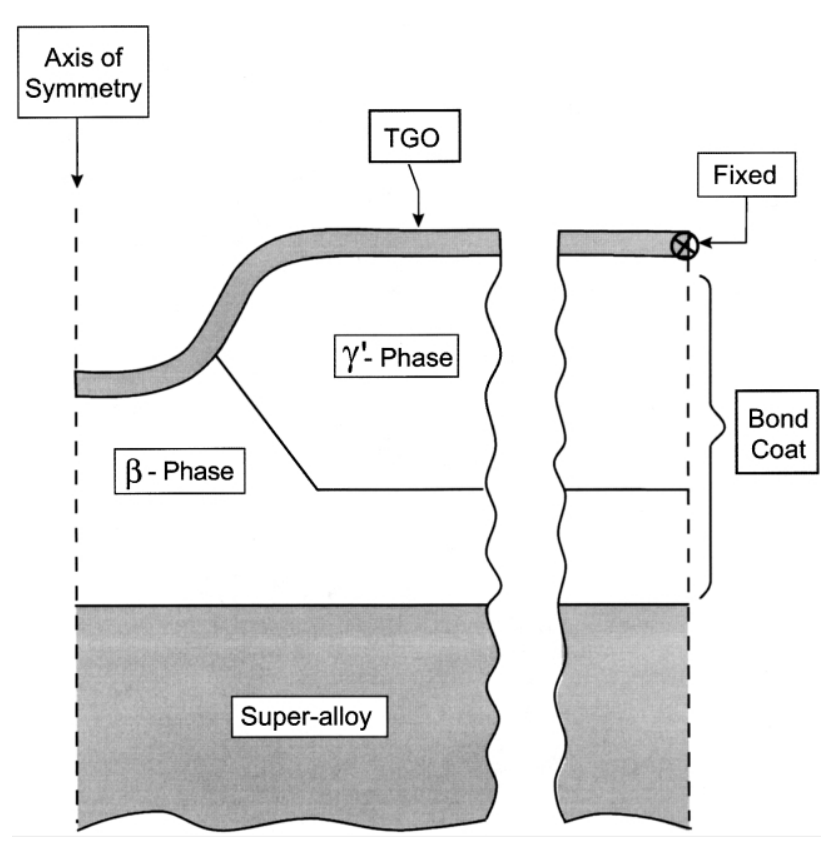

Fig. 3. The axisymmetric model used for the present calculations showing the location of the $\beta / \gamma^{\prime}$-phases.

different values of the high-temperature strengths are assigned to the $\beta$ - and $\gamma^{\prime}$-phases. In the following, the high-temperature yield strengths will simply be referred to as 'yield strength'.

At the temperature maximum, the TGO experiences thickening and lengthening strains. The lengthening strain dominates the TGO instability. Accordingly, to simplify the calculations, the thickness can be held constant (at its average) and the lengthening strain imposed during each thermal cycle. In this case, the lengthening strain is taken to be representative of that for a furnace cycle test, $\varepsilon_{\mathrm{g}}=10^{-3}$.

At the highest temperature in the cycle, the TGO has a maximum sustainable stress, governed by creep/ yielding. This stress is equated to the experimentally determined TGO growth stress. Once this stress is reached in the TGO, in-elastic deformation prohibits further elongation, causing the growth strain to be redistributed as thickening. At temperatures below the maximum, the TGO is elastic.

The bond coat is considered to have a different thermal expansion coefficient than the substrate. In addition, different values are assigned to the $\beta$ - and $\gamma^{\prime}$ phases.

Initial geometric imperfections are introduced at the bond-coat/TBC interface, with shape and size typical of that associated with the interface roughness created by grit blasting of the bond coat, prior to TBC deposition. The shape assumed is shown in Fig. 3. These dimensions and shapes are based on observations made on this specific thermal barrier system (Fig. 2). The shape sensitivity was studied in Ref. [11], and that the total amplitude change invariant with respect to initial shape. The amplitude growth is monitored in the numerical investigations, corresponding to the growth of the imperfection.

The calculations follow the bond-coat/TGO deformation upon thermal cycling while the TGO is subject to an elongation strain per cycle. In the following simulations, the superalloy is elastic.

\section{Simulation results}

\subsection{Preliminary results}

First of all, a simplified model without the substrate and the TBC layer has been used (Fig. 4a). The curvature of the TGO layer is identical for the above two phases, $\beta$ and $\gamma^{\prime}$. The $\beta$-phase has significantly lower yield stress than the $\gamma^{\prime}$-phase. For modeling purposes we selected to use high-temperature yield strengths of 20 and $120 \mathrm{MPa}$, respectively.

After 12 cycles, the displacement of the TGO layer in the normal direction is an order of magnitude higher in the $\beta$-phase than in the $\gamma^{\prime}$-phase (Fig. 4b). (The tangential displacement is negligible.) This is mainly due to the higher yield stress of the $\gamma^{\prime}$-phase but also to a lower extent to its smaller thermal expansion mismatch with the TGO layer.

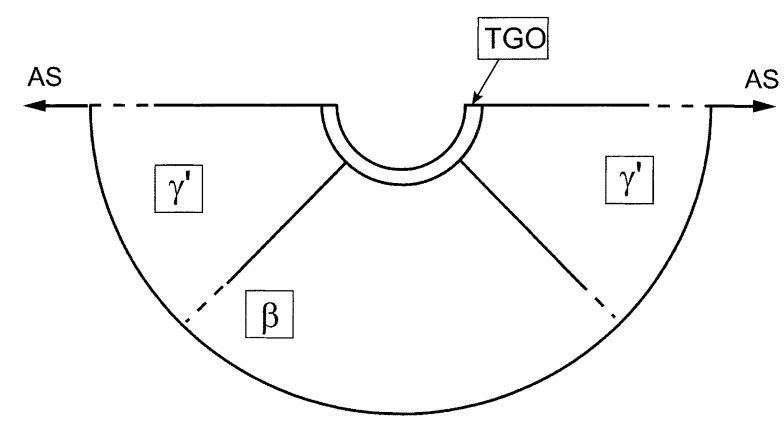

A.S.

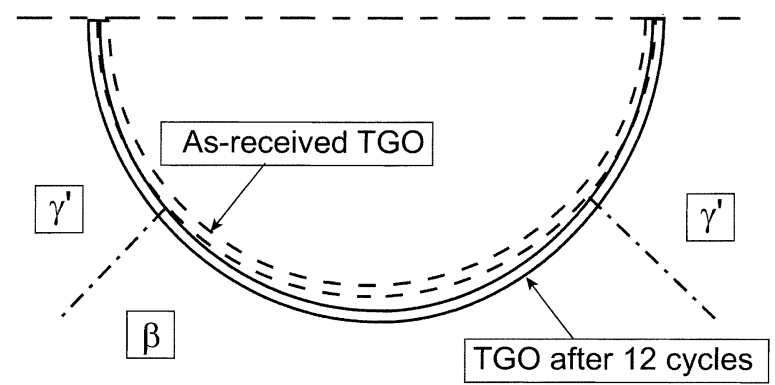

Fig. 4. The simplified axisymmetric model used for the preliminary simulations. (a) The location of the $\beta$ - and $\gamma^{\prime}$-phases of the bond coat is symmetric. (b) The deformation of the TGO after 12 cycles: larger deformation downward in the $\beta$-phase. $\left(\sigma_{\mathrm{Y}}(\beta)=20 \mathrm{MPa}, \alpha(\beta)=18\right.$ $\mathrm{ppm} /{ }^{\circ} \mathrm{C}, \sigma_{\mathrm{Y}}\left(\gamma^{\prime}\right)=120 \mathrm{MPa}, \alpha\left(\gamma^{\prime}\right)=14 \mathrm{ppm} /{ }^{\circ} \mathrm{C}$. $)$ 
Table 1

Material properties used in the model

\begin{tabular}{lllc}
\hline & $E(\mathrm{GPa})$ & $v$ & $\alpha$ \\
\hline TGO & 400 & 0.2 & 8.6 \\
Bond coat & 200 & 0.3 & 14 \\
Substrate & 200 & 0.3 & 16 \\
\hline
\end{tabular}

The displacement of the TGO layer mainly occurs at high temperature. The system endures an increase of stress fromtwo sources: (i) the mismatch of thermal expansion coefficient between the TGO and the bond coat, (ii) and the lateral growth of the TGO. Under these test conditions, the yield stress of the $\beta$-phase is reached rapidly, implying the plastic deformation of the $\beta$-phase. Simultaneously, the lateral growth of the TGO takes place, and is readily accommodated by the yielding of the $\beta$-phase. On the contrary, the yield stress of the TGO above the $\gamma^{\prime}$-phase is reached before the yield stress of the $\gamma^{\prime}$-phase, inducing a large plastic deformation of the TGO above the $\gamma^{\prime}$-phase. Consequently, the lateral growth of the TGO is limited above the $\gamma^{\prime}$-phase. Only a slight deformation of the $\gamma^{\prime}$-phase occurs, whereas the larger deformation is localized in the middle of the $\beta$-phase.

These preliminary results are consistent with the experimental observations, which show that the propagation of the instabilities occurs preferentially downwards, in the $\beta$-phase.

\subsection{Layered model}

In the following, the layered model (Fig. 3) will be considered, taking into account the effect of the substrate but ignoring the TBC layer. (The effect of the TBC layer will be discussed in a later study [21].) Based on experimental observation and on the preliminary report discussed above, the instability will be located above the $\beta$-phase. The geometry of this model represents the system after approximately $30 \%$ of its lifetime. At this lifetime, the $\gamma^{\prime}$-phase domains are large relative to the instabilities and cannot be neglected. We will compare to the case when the instability is located above the $\gamma^{\prime}$. In the following, the (high-temperatures) yield strengths are assumed to be $\sigma_{\mathrm{Y}}^{\beta}=20 \mathrm{MPa}$ and $\sigma_{\mathrm{Y}}^{\gamma^{\prime}}=120 \mathrm{MPa}$, for the $\beta$ - and $\gamma^{\prime}$-phases, respectively. The properties used are summarized in Table 1.

Before proceeding, we note that the thermal expansion misfit of the bond coat, $\alpha_{\mathrm{bc}}$, to the substrate, $\alpha_{\mathrm{sub}}$, influences the development of the instability. It causes the bond coat to become fully plastic upon thermal cycling, rather than exhibiting the local plasticity around the imperfection found in the case of absent misfit $[9,17]$. In this case, we will assume that the misfit between the two bond-coat phases vanishes, $\alpha_{\mathrm{bc}}=\alpha_{\gamma^{\prime}}=$ $\alpha_{\beta}=14 \times 10^{-6} /{ }^{\circ} \mathrm{C}$, while the misfit between bond coat and substrate is constant, $\alpha_{\mathrm{bc}}-\alpha_{\mathrm{sub}}=-2 \times 10^{-6} /{ }^{\circ} \mathrm{C}$ [23].

Benchmark results are obtained for the case of homogeneous bond coat (Fig. 5). Two cases of bond-coat yield strength are studied: (i) the bond coat consist of pure $\beta$-phase: $\sigma_{Y}^{\mathrm{bc}}=\sigma_{Y}^{\beta}=20 \mathrm{MPa}$ and (ii) the bond coat consist of pure $\gamma^{\prime}$-phase: $\sigma_{Y}^{\mathrm{bc}}=\sigma_{Y}^{\gamma^{\prime}}=120 \mathrm{MPa}$. The case of lower yield strength results in larger amplitude changes (Fig. 5), which is consistent with previous published results [9]. However, the deformation is not self-similar, i.e. the deformation obtained for the lower yield strength cannot be achieved by magnifying the deformation obtained fromthe higher yield strength. This is primarily related to two factors: (i) for higher yield strength, the yielding tends to be limited to high stress areas around the imperfection, and (ii) for the lower yield strengths, larger regions are affected by the yielding and in addition, yielding occurs during oxidation. Thus, the simulations show that morphological instabilities are more likely to occur in the $\beta$-phase. This is consistent with experimental observations.

The influence on the amplitude change of $\beta$ - and $\gamma^{\prime}$ phase locations is investigated in Fig. 6 . When the $\beta$ phase is located at the bottomof the imperfection (Fig. 6a) significantly larger downwards deflection are

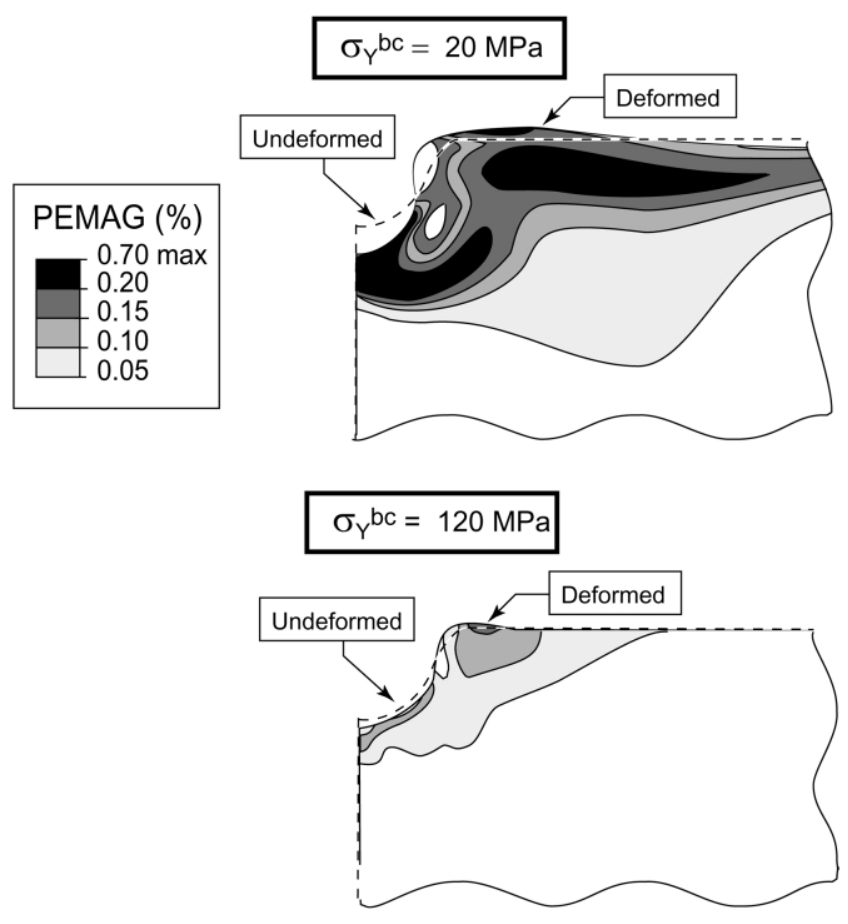

Fig. 5. The deformation of the TGO-bond-coat interface and the accumulation of plastic strain after 24 cycles for various bond-coat yield strength for a homogeneous bond coat: (a) $\sigma_{\mathrm{Y}}^{\mathrm{bc}}=\sigma_{\mathrm{Y}}^{\beta}=120 \mathrm{MPa}$ and (b) $\sigma_{\mathrm{Y}}^{\mathrm{bc}}=\sigma_{\mathrm{Y}}^{\gamma^{\prime}}=20 \mathrm{MPa} .\left(\alpha_{\mathrm{bc}}=\alpha_{\gamma^{\prime}}=\alpha_{\beta}=14 \times 10^{-6} /{ }^{\circ} \mathrm{C}, \alpha_{\mathrm{bc}}-\alpha_{\mathrm{sub}}=\right.$ $-2 \times 10^{-6} /{ }^{\circ} \mathrm{C}$.) 


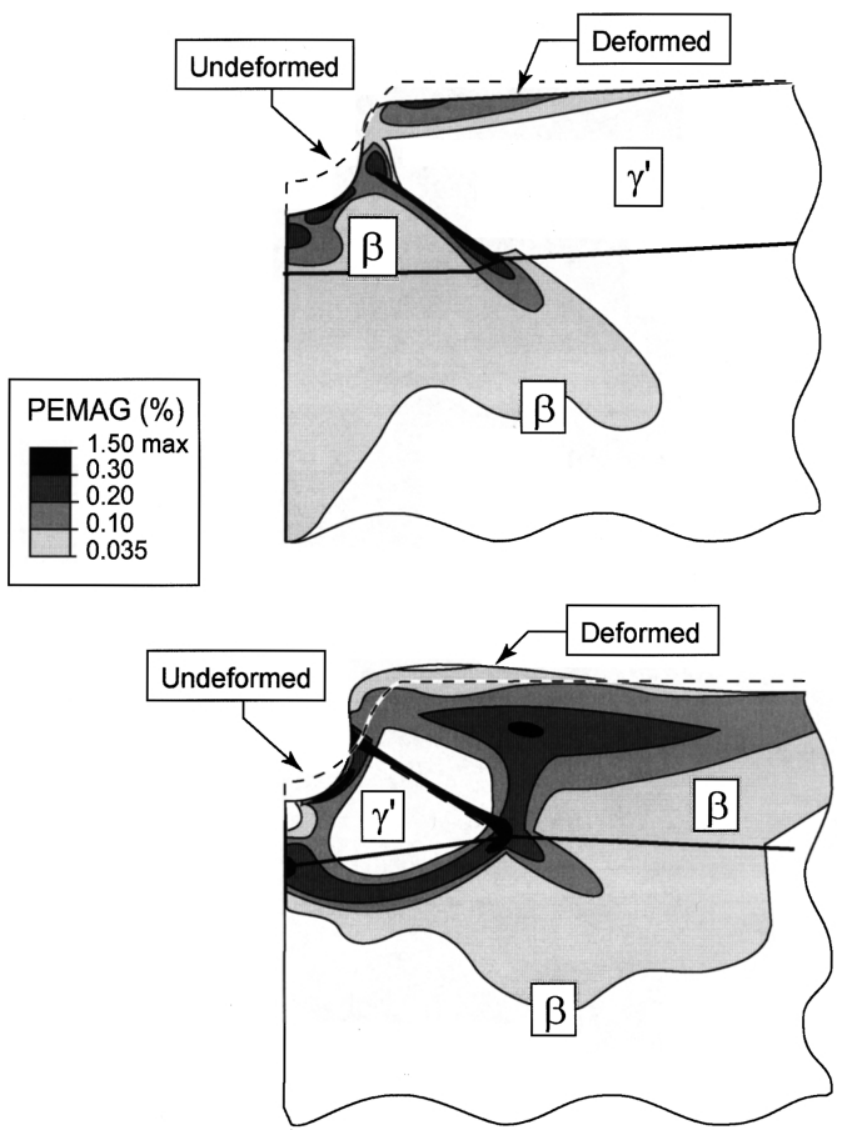

Fig. 6. The deformation of the TGO-bond-coat interface and the accumulation of plastic strain after 24 cycles for microstructures: (a) $\beta$ phase at the bottomof the undulation and (b) $\gamma^{\prime}$-phase at the bottom of the undulation. $\left(\sigma_{\mathrm{Y}}^{\beta}=20 \mathrm{MPa}, \sigma_{\mathrm{Y}}^{\gamma^{\prime}}=120 \mathrm{MPa} . \alpha_{\mathrm{bc}}=\alpha_{\gamma^{\prime}}=\alpha_{\beta}=\right.$ $14 \times 10^{-6} /{ }^{\circ} \mathrm{C}, \alpha_{\mathrm{bc}}-\alpha_{\mathrm{sub}}=-2 \times 10^{-6} /{ }^{\circ} \mathrm{C}$.)

achieved compared to when $\gamma^{\prime}$ is located at the bottom (Fig. 6b). Fromthe contours corresponding to accumulation of plastic strain, it is seen that when $\beta$ is located in the bottom, the plastic field extends downwards. If the $\gamma^{\prime}$ is located at the bottom, the high strength $\gamma^{\prime}$ acts almost as rigid body, pushing the softer $\beta$ aside. Thus, in this case, significantly more plastic strain is accumulated on the side of the imperfection resulting in upwards motion at the periphery of the imperfection. ${ }^{1}$

In summary, by comparing the downwards deflection of a bond coat where the location of the $\beta$ - and $\gamma^{\prime}$ phases is varied, it is seen that the case of $\beta$-phase at the bottom of the undulation promotes morphological instabilities.

\footnotetext{
${ }^{1}$ The peripheral upwards motion will be prevented if the interface between top coat and TGO is intact and has been seen to interact with the growth and coalescence of cracks [22]. The interaction with the top coat is explored in Ref. [21].
}

\section{Conclusion}

The present article has shown that a previously developed simulation procedure can be used to incorporate microstructure in the bond coat and that the effects duplicate experimental observations. In particular, the presence of the $\gamma^{\prime}$-phase next to the TGO reduces its distortion, attributed to its superior high-temperature strength. In regions where the $\beta$-phase exists adjacent to the TGO, it distorts and the TGO propagates downward, as it lengthens, in direct correspondence with experimental observations. Moreover, upward displacements can also take place depending on the thermomechanical properties of the different phases. These displacements may play a role in the propagation of the cracks, and therefore the lifetime of the system.

\section{References}

[1] M. Gell, K. Vaidyanathan, B. Barber, J. Cheng, E. Jordan, Metall. Mater. Trans. A 30 (1999) 427-435.

[2] P.K. Wright, A.G. Evans, Curr. Opin. Solid State Mater. Sci. 4 (1999) 255-265.

[3] D.R. Mumm, A.G. Evans, Acta Mater. 48 (2000) 1815-1827.

[4] D.R. Mumm, A.G. Evans, I. Spitsberg, Acta Mater. 49 (2001) 2329-2340.

[5] A.G. Evans, D.R. Mumm, Prog. Mater. Sci. 46 (2001) 505-553.

[6] V.K. Tolpygo, D.R. Clarke, Acta Mater. 48 (2000) 3283-3293.

[7] V.K. Tolpygo, J.R. Dryden, D.R. Clarke, Acta Mater. 46 (1998) 927.

[8] M.Y. He, A.G. Evans, J.W. Hutchinson, Acta Mater. 48 (2000) 2593-2601.

[9] A.M. Karlsson, A.G. Evans, Acta Mater. 49 (2001) 1793-1804.

[10] A.M. Karlsson, J.W. Hutchinson, A.G. Evans, J. Mech. Phys. Solids 50 (2002) 1565-1589.

[11] A.M. Karlsson, C.G. Levi, A.G. Evans, Acta Mater. 50 (2002) 1263-1273.

[12] A.M. Karlsson, J.W. Hutchinson, A.G. Evans, Mater. Sci. Eng. A 351 (2003) 244-257.

[13] M. Bartsch, B. Baufeld, E.R. Fuller, Proceedings of the 27th Annual Conference on Composites, Advance Ceramics and Materials, January (2003), in press.

[14] R.C. Pennefather, D.H. Boone, Surf. Coat. Technol. 1-3 (1995) $45-57$.

[15] M.W. Chen, R.T. Ott, T.C. Hufnagel, P.K. Wright, K.J. Hemker, Surf. Coat. Technol. 163-164 (2003) 25-30.

[16] Y. Zhang, J.A. Haynes, B.A. Pint, I.G. Wright, W.Y. Lee, Surf. Coat. Technol. 163-164 (2003) 19-24.

[17] A.M. Karlsson, J. Eng. Mater. Technol., in press.

[18] A.M. Karlsson, Proceedings of the 27th Annual Conference on Composites, Advance Ceramics and Materials, January, 2003.

[19] D. Pan, M.W. Chen, P.K. Wright, K.J. Hemker, Acta Mater. 51 (2003) 2205-2217.

[20] S. Darzens, D.R. Mumm, D.R. Clarke, A.G. Evans, Metall. Mater. Trans. A 34 (2003) 511-522.

[21] S. Darzens, A.M. Karlsson, A.G. Evans, in preparation.

[22] T. Xu, M.Y. He, A.G. Evans, Acta Mater. 51 (2003) 2807-3820.

[23] J.A. Haynes, B.A Pint, W.D. Porter, I.G. Wright, Materials at High Temperature, January, submitted for publication. 